LEWYTSKA Lilia,

Ph. D., lecturer of German Philology Department,

Bohdan Khmelnytsky National University at Cherkassy

\title{
TENDENCIES OF MULTICULTURAL DEVELOPMENT OF EDUCATION AT UNIVERSITIES IN GERMANY
}

Abstract. The study analyzes main trends of multicultural education in the universities of Germany. Specifically, the article considers the concepts of multiculturalism in pedagogy, reveals objectives and principles of multicultural education in higher educational establishments of Germany. It also discovers historical and social-economic aspects of progress of multicultural education in universities of Germany.

Purpose. The article is targeted at analyzing current research trends of multicultural education in Germany and outlining the corresponding chronologic periods.

Result. The study reveals the perspectives of possible implementation of positive experiences of multicultural education at German Universities into the Ukrainian system of Higher Education.
Conclusion. The conducted research has allowed arriving at the conclusion that the signs of multiculturalism comprise promotion of humanization, democratization, internationalization, multilingualism, openness and accessibility of education. Furthermore, multiculturalism implies employing definite techniques of implementing the Bologna Declaration in the multicultural space of German universities.

Keywords: multicultural education; ethnocentrism; the dominant ethnic group; cultural autonomy; tolerance; cultural diversity and pluralism.

Одержано редакиією 07.01.2019 Прийнято до публікаиіï 15.01.2019

DOI 10.31651/2524-2660-2019-1-37-41

ORCID 0000-0002-8214-6059

АТАКИШИЕВА Айсемь Ислам гызы,

докторант кафедры педагогики и психологии, Бакинский славянский университет, Азербайджан e-mail: bitkovskayay@inbox.ru

УДК 378.146

\section{КУАЬТУРНО-ОБРАЗОВАТЕАЬНОЕ ПРОСТРАНСТВО ВУЗА КАК ВАЖНЫЙ ФАКТОР ФОРМИРОВАНИЯ ПЕДАГОГИЧЕСКОЙ КУАЬТУРЫ СТУДЕНТОВ}

Статья рассматривает вопросы влияния культурно-образовательного пространства вуза на профессионально-педагогическое становление студентов, повышения уровня их духовно-интеллектуальной подготовки. В статье анализируются формы и методы учебновоспитательного проиесса вуза, наиболее наиелено направленные на формирование педагогической культуры студентов. Статья раскрывает богатейшие возможности педагогического коллектива в личностно-соииальной и профессионально-педагогической самореализаиии студентов.

Ключевые слова: культурнообразовательное пространство вуза; студенты; учебная деятельность; межличностные отношения; профессиональная подготовка; преподавательский коллектив.

Постановка пробиемы. Совершенствование демократических преобразований нашего общества, повышение уровня духовно-интемлектуальной, социально-профессиональной подготовки подрастающего покомения, углубления его мировоззрения и расширения научного кругозора, настоятельно требуют кардинального улучшения и повышения эффективности процессов обучения и воспитания молодежи. Позитивное разрешение этих задач однозначно зависит от уровня теоретической и практической подготовленности студенческой молодежи - активного авангарда общего моло- дежного движения страны. Высшая школа страны, являющаяся мощной научной, образовательной и воспитатемьной силой общества должна способствовать тому, чтобы студенты, получающие образование в ее стенах, всегда были нацелены на профессиональнопедагогическое и и социальнонравственное самосовершенствование, высокий уровень социальнопрофессиональной самореализации.

Цемь - Показать культурнообразовательное пространство вуза как важный фактор формирования педагогической кумьтуры студентов.

изиожение основного материала. Высшая школа страны должна поднять уровень эффективности учебновоспитатемьный работы до такой степени, чтобы студенческая молодежь могма наиболее благоприятно самореализоваться в жизни как творческая, конструктивно-созидательная сима, профессионально востребованная обществом, как серьезная структурная составцяющая процесса демократического развития страны. Именно от уровня духовноинтемлектуального подготовки молодых юдей, их общей и профессиональнопедагогической кумьтуры, социальной активности, нацеленности на професси- 
ональное самовыражение и самосовершенствование, зависит качеств и действенность прилагаемых ими усимий мичностно-социальной и профессиональной самореализации.

Проблема формирования педагогической культуры студентов вузов предполагает решение в органическом единстве двух наиболее важных вопросов: а) организация эффективного процесса формирования педагогической культуры у будущего специалиста, который будет заниматься педагогической деятемьностью (учитель, воспитатель, работник административных педагогических органов, общественная организация). Peшение этого аспекта проблемы обязательно требует учета в процессе формирования педагогической культуры социально-психологических, возрастных особенностей, уровня общей кумьтуры и нравственной саморегуляции молодых мюдей; б) непосредственная теоретическая, практическая и методическая подготовка самих студентов, с точки зрения,

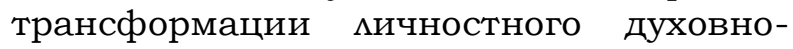
интемлектуамьного материала свое ближайшее окружение (друзья, товарищи, студенты по учебной группе, вузу и т.д.).

Кумьтурно-образовательное пространство вуза в своем влиянии на студентов оптимистически создает условия и предпосылки их творческого развития и самореацизации, способствует постепенному повышению уровня мичностной педагогической кумьтуры студентов, располагает большими возможностями совершенствования

духовноинтемлектуального мира молодых мюдей. Кумьтурно-образовательное пространство высшей школы целенаправленно ориентирует студентов на повышение уровня своей творческой индивидуацьности, создает необходимую платформу своеобразной трансформации социальнопрофессиональных норм и требований в мичностные установки и убеждения, совершенствует систему профессиональноценностных ориентаций момодых мюдей. Эффективность работы высшей школы

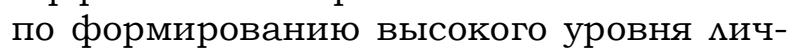
ностной педагогической кумьтуры студентов в значительной степени зависит от единства и совмещения в одном направлении воздействия всех факторов (внутренних и внешних) на студенческую момодежь, формирования их профессиональных интересов, ответственного отношения к учебной и творческой дея- тельности молодых мюдей [1, с.99]. Как отмечали $\Lambda$. А. Головей, $\Lambda$. В. Рыкман и другие исследователи: "На формиро вание интемлектуальных функций наибольшее вмияние оказывает не только социальное взаимодействие, но и внимание семьи к когнитивному развитию подростков" [2, с. 99].

Весь учебно-воспитательный процесс вуза, вкцючающий в себя различные формы учебной и внеаудиторной работы, является составной частью культурнообразовательного пространства вуза и направцяет студентов на дальнейшее повышение уровня эфффективности и действенности, прилагаемых ими усимий в плане социально-профессиональной самореализации. Весь комплекс учебных и внеучебных форм деятельности, про-

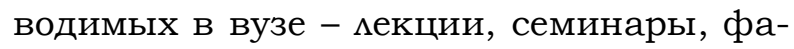
культативы, студенческая научная деятельность, написание рефератов, дипломных работ, подготовка научных докладов и вступление на различных конференциях, диспуты, проведение размичных тематических вечеров вопросов и ответов, многочисленные “круглые стомы", приглашение именитых гостей на встречу со студентами, разцичные виды социальных и профессиональных мероприятий, работы кружков, активность студентов в общественной деятельности и т.д. - все призвано раскрыть, углубить, совершенствовать

духовноинтелмектуальный, профессиональный потенциал молодых мюдей, повысить уровень их общей и профессиональнопедагогической кумьтуры. Духовноинтемлектуальный, профессиональнотворческий потенциал студентов может особенно четко и выражено раскрыться в профессионально-педагогической деятельности высшей школы. Весь ход учебно-воспитательного процесса в вузе, систематическое и целенаправленное решение размичных профессиональнопедагогических задач, создание наибомее благоприятных условий и предпосылок

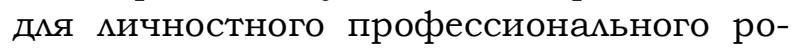
ста молодых шению эффективности процесса формирования педагогической культуры студентов.

Как отмечает в своей комлективной монографии исследователи Н. П. Аысикова, Н. Р. Вакулич, О. И. Алимаева, Е. В. Аиствина: “Интеграция культуры и образования позволяет создать в высшем учебном заведении оптимальные усмовия 
для гуманизации процесса обучения, самореализации, позитивного взаимодействия субъектов образования, выбора образоватемьных услуг" [3, с. 67]. Педагогический комлектив вуза, выступающие как важный составляющий фактор культурно-образоватемьного пространства высшей школы, оказывает решающее влияние на процесс профессионального формирования студенческой молодежи $[4$, с. 67]. От уровня профессионамьной подготовленности преподавателей вуза, их нацеленности $\mathrm{K}$ использованию в учебно-воспитательном процессе разцичных инновационных технологий, новаторских приемов и методов работы будет зависеть реальная заинтересованность студенческой момодежи $\mathrm{K}$ профессионально-педагогической деятельности, к повышению уровня своей профессиональной самореализации и востребованности обществом. Благодаря своему нравственно и профессионально высокому уровню развития, доброжелательным ичностным качествам, преподаватели вузов не только формируют у студентов активную, действенную систему научных знаний, но и способствуют развитию таких качеств как могика мышления, инициативность, самостоятельность суждений, профессиональная актив-

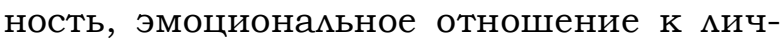
ностному духовно-интелцектуальному потенциалу.

Педагогический комлектив, цеменаправленно проводя работу по формированию у студентов высокого уровня педагогический кумьтуры, одновременно закладывает серьезные основы позивитизации межличностных отношений, выводя сам процесс общения среди студентов на качественно новый, высокий уровень. Как подчеркивает А. А. Һобанов: "Вступая в общение, оба партнера фиксируют особенности внешнего облика и эмоционального состояния друг друга, пытаются понять причины поведения партнера, проникнуть в мотивы его высказываний и поступков" [5, c. 22].

С целью выявления возможностей влияния культурно-образовательного пространства вуза на формирование педагогической кумьтуры студентов мы провели своеобразный мини-опрос среди студентов всех четырех курсов Бакинского славянского университета. Наш мини опрос представцял собою анкетирование, беседы, изучение и анализ мнений студентов и преподавателей вуза. Этой работой бымо охвачено 137 студен- тов I и IV курсов. Вопросов в анкетах, в

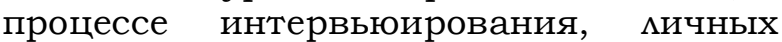
бесед бымо задано немало, однако, мы считаем, что рамки нашей статьи не позволяют привести их в реальном количестве и, на наш взгляд, чтобы наиболее полно сложить представление о названии нашей статьи, правомерно будет привести в качестве примера несколько самых главных вопросов, которые, по нашему мнению, достаточно емко и поцно концентрируют в себе саму идею проведения такого своеобразного мини-опроса. Вопросы всем студентам I и IV курсов обучения выглядеми следующим образом (в концентрированном виде). 1) «Как Вы понимаете выражение "педагогическая кумьтура студентов»?»; 2) “Как Вы понимаете выражение "культурнообразовательное пространство вуза»?»; 3) «Как Вы думаете, каким образом культурно-образовательное пространство ву-

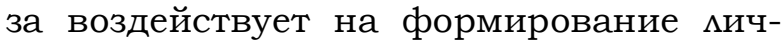
ности студентов в частности на формирование их педагогической культуры?"; 4) “Что Вы можете предложить дия существенного повышения эффективности воздействия культурно-образовательного

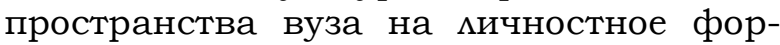
мирование студентов и, в частности, на

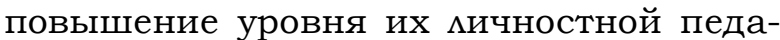
гогической кумьтуры?». Ответы студентов на предмагаемые ими вопросы позволили нам сделать соответствующие выводы и составить определенную характеристику $\quad$ ичностно-творческих возможностей студентов всех четырех курсов.

Следует подчеркнуть и такой факт среди студентов I курса много молодых мюдей, которые охотно откиикаются на формы воздействия культурнообразовательного пространства вуза (хо-

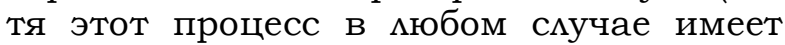
место и фиксируется на уровне подсознания), но есть и студенты, отличающиеся отсутствием интереса к педагогической деятельности, безынициативные, несамостоятельные. Это состояние можно объяснить с еще не сложившимся кругом профессиональных интересов,

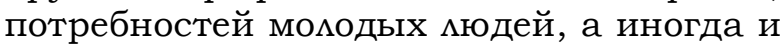
недостаточно оформленной системой духовных ценностей. Нами в ответах студентов была замечена следующая тенденция: студенты I курса убеждены, что дмя их успешной профессионамьнопедагогической самореализации в реальной действительности педагогическим комлективом вуза им будет преподнесены специальные, всеобъемлющие профессиональные знания, усвоив которые, 
они могут быть спокойны с точки зрения своего профессионально-педагогического самовыражения.

Студенты II курса обучения (как видно из их ответов) начинают более предметно относиться к различным мероприятиям вуза, стараются узнать для себя что-то новое, принять активное участие в их подготовке. Бымо замечено из ответов студентов, что мотивы участия их в общевузовских мероприятиях из категории "условных" ("цожных") пере-

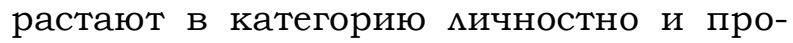
фессионально заинтересованных. В ответах студентов II курса обучения уже можно было проследить попытки (и только) предложения опредеменных рекомендаций по повышению эффективности процесса $и$ иностно-профессионацьного формирования молодых мюдей. Например, студенты предлагают увеличить комичество общевузовских мероприятий, ориентированных на стимулирование профессионально-педагогического самосовершенствования (Аекции, диспуты, комлективное обсуждение профессионально направленных вопросов, приглашение преподавателей-новаторов, магистрантов, работников местных административных органов, курирующих вопросы образования и профессиональной востребованности, чаще привлекают студентов к научно-исследовательской работе, к подготовке рефератов, докладов, тезисов, статей).

Студенты III курса обучения, собственно, уже составцяющие костяк студенческого комлектива вуза отвечали на наши вопросы более предметно, взвешенно, не отдалялась от тематики поставценных вопросов (что иногда наблюдалось среди ответов студентов I и II курса обучения). Студенты этого курса обучения уже с профессионацьной точки зрения давали опредемения выражениям "культурно-образовательное пространство", "педагогическая кумьтура". Было замечено, что они нацелены по получение более обширного объема научных знаний, навыков, приемов работы с научной $и$ тературой. В процессе прохождения ими обязатемьной педагогической практики в средних общеобразовательных школах старались максимально полно использовать на уроках комплекс полученных ими научных знаний, совещались с классными руководителями, с руководителями педагогической практики, активно обсуждали со специалистами проводимые ими уроки. Студенты III курса обучения прекрасно понимахи сущность вопроса о воздействии кумь- турно-образовательного пространства вуза на формирование мичности студентов, в частности, на формирование их педагогической кумьтуры. Рекомендации студентов этого курса носими узко специализированный характер, например, они высказывали пожелания, чтобы научная информация, научные знания, преподаваемые им со стороны преподавателей, не носими, прежде всего, обучающий характер.

Студенты IV курса обучения (выпускной курс) практически уже сформированные в истинном значении этого слова (у них отсутствует только мишь активная, широкая база профессиональнопедагогической деятемьности). По ответам студентов этого курса можно определить, что они хорошо знакомы с учебно-воспитательным процессом вуза, прекрасно знают его сильные стороны и имеющиеся недостатки, хорошо ориентируются, аргументируют и комментируют значение чисто профессиональных выражений и могут на достаточно приемлем уровне найти позитивные пути разрешения той ими иной профессиональной задачи. Студенты IV курса обучения никогда не комментировали в своих ответах сущность педагогической культуры в отрыве от общей культуры мичности. Они прекрасно ориентирова$\Lambda и с ь$ в вопросах проявления педагогиче-

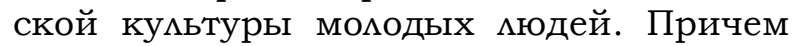
ответы студентов этого курса отмичались маконичностью, аргументацией и знанием обсуждаемого вопроса. Нами было замечено, что на IV курсе обучения профессионально-педагогическая активность студентов нескоцько снижается (это бымо выражено в их ответах на поставценные вопросы). Студенты мотивировали это тем, что полная акцентуация их внимания сейчас направлена на вопросы исключитемьно профессиональной самореализации в жизни.

Проблема формирования педагогической культуры студентов под влиянием кумьтурно-образовательного пространства очень актуальна, обширна, многофакторна и многоаспекта. Естественно, в рамках одной статьи практически невозможно дать полную, всеобъемлющую характеристику тем факторам, которые в той или иной степени активности спо-

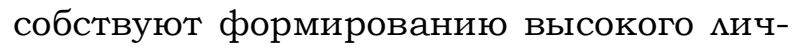
ностного уровня педагогической кумьтуры студентов. Однако, даже тот маленький мини-опрос, который мы провели среди студентов Бакинского славянского университета, позволиц нам сделать опредеменные выводы, которые, как мы 
считаем будут в обязательной степени учитываться в дальнейшем при организации учебно-воспитательного процесса в вузе. Анализируя полученные нами данные мы пришии к мнению, что, хотя влияние культурно-образовательного пространства вуза на формирование мичности студентов и их педагогической кумьтуры бесспорно и безусловно, все же этот процесс должен самым серьезным образом на профессиональной основе постоянно регулироваться и оставаться в зоне повышенного интереса и внимания всего педагогического комлектива вуза.

Выводы и перспективы дамьнейших исследований. Полученные нами данные свидетемьствуют, что студенты, в общем-то, правильно и верно понимают вопросы вцияния культурнообразовательного пространства вуза на их $\Lambda$ иностное, профессиональнопедагогическое формирование и, что было заметно в ответах, стремятся посвоему, а иногда и с профессиональной помощью преподавателей, совершенствовать вмияние культурнообразовательного пространств вуза на их мичностно-профессиональное самовыражение, своеобразно конструируя модемь дружного, сплоченного студенческого комлектива с широкими возможностями, в высоким уровнем педагогической культуры каждого студента.
Список бибанографических источников

1. Байкова $\Lambda$.А. Педагогическое мастерство и педагогическая этика. М.: Информ, 2001, 298 с.

2. Головей $\Lambda$. А., Рыкман $\Lambda$. В. и др. Профессиональное развитие кичности: начало пути. СПб., Нестор-Историк, 2015, 336 с.

3. Аысикова Н. П., Ракулич Н. Р., Алимаева О. И., Ииствина Е. В. Культурно-образовательное пространство современного человека / Под ред. Проф. Ю.Г. Голуба. Саратов, изд-во "Саратовский источник", 2010, 167 с.

4. Артюхина А. И. Профессионально-личностное развитие студентов в образовательной среде вуза. Волгоград, ВГМУ, 2006, 122 с.

5. Мобанов А. А. Основы профессиональнопедагогического общения. М.: Академия, 2004, 192 c.

6. Котлярова А. И., Тягунова Ю. В. Педагогика высшей школы. Челябинск: Изд. Центр ЮУрГУ, 2012, 129 c.

\section{References:}

1. Baykova L.A. (2001). Pedagogical skills and pedagogical ethics. M.: Inform. 298 p.

2. Golovey L.A. (2015). Rykman L.V. and others. Professional personal development: the beginning of the path. SPb., Nestor-Historian. 336 p.

3. Lysikova N.P., Rakulich N.R., Alimaeva O.I., Listvina E.V. (2010). Cultural and educational space of modern man / Ed. Prof. Yu.G.Goluba. Saratov, publishing house "Saratov source". $167 \mathrm{p}$.

4. Artyukhina A.I. (2004). Professional and personal development of students in the educational environment of the university. Volgograd, VSMU. 122 p.

5. Lobanov A.A. (2004). Fundamentals of professional and pedagogical communication. $\mathrm{M}$.: Academy. $192 \mathrm{p}$.

6. Kotlyarova A.I., Tyagunova Yu.V. (2012). Higher School Pedagogy. Chelyabinsk: Izd. Center for SUSU. 129 p.

\section{ATAKISHIYEVA Aysel, \\ post-graduate student of the department Pedagogy and Psychology \\ Baku Slavic University, Azerbaijan \\ CULTURAL AND EDUCATIONAL UNIVERSITY ENVIRONMENT AS AN IMPORTANT FACTOR OF PROMOTING PEDAGOGICAL CULTURE AMONG STUDENTS}

Abstract. This study focuses on the important pedagogical issue - the acquisition of pedagogical culture by higher schools students. Specifically, it emphasizes the significance of that process in professional development of young people, highlights a role of a pedagogical collective in increasing students' professional ability, summarizes the ideas of authoritative scholars on the issue under discussion, and explores the conditions conducive to shaping pedagogical culture of cognizing subjects. A special emphasis is placed on family education of students. The article also propounds corresponding recommendations for promoting pedagogical culture of higher schools students.

The purpose of the article is to disclose and analyze the culture-educational environment of higher schools as an important factor of fostering pedagogical culture of students.

Originality. The study presents the results of a pedagogical experiment conducted as a mini-interrogation of university students of four years of study (it comprised questionnaires, interviews, personal conversations, observations of activities, etc.), aiming at identifying and analyzing the influence of cultural and educational academic environment on the professional and pedagogical advancement of teacher-trainees, their spiritual and intellectual self-improvement.
Results. The summarized results of the carried out research triggered off the formulation of relevant recommendations for improving the efficiency of the process targeted at shaping pedagogical culture of University students.

Conclusion. The obtained data indicate that commonly, students are aware of the positive influence of the academic environment on their personal, professional and pedagogical development. Students' answers signify that they are oriented at professional growth, though each of them has their own developmental trajectory. Some of them are very independent in their aspirations, some gladly accept the assistance of their families and University teachers. Simultaneously, all of them recognize that the cultural and educational environment of the University is conducive to their personal and professional selfexpression, being a unique model of constructing a pedagogical team, which opens broad perspectives for developing their professional culture.

Keywords: cultural and educational environment of higher school; University students; educational activity; inter-personal relations; professional training; pedagogical collective.

Одержано редакиією 08.01.2019 Прийнято до публікаиї̈ 17.01.2019 